\title{
Characterization of invasive Neisseria meningitidis strains isolated at the Children's Hospital of Tunis, Tunisia
}

A. Saguer, ${ }^{1}$ H. Smaoui, ${ }^{1}$ M-K. Taha ${ }^{2}$ and A. Kechrid ${ }^{1}$

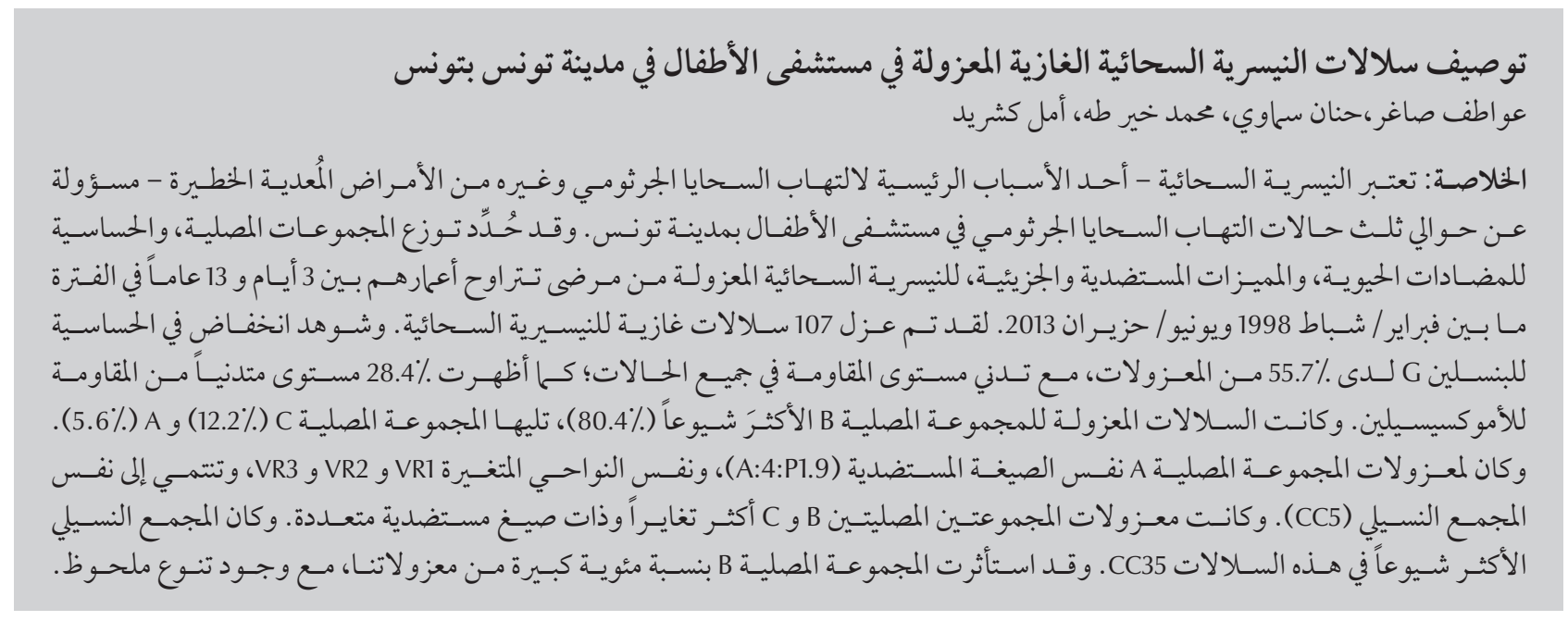

ABSTRACT Neisseria meningitidis, a leading cause of bacterial meningitis and other serious infections, is responsible for approximately one-third of cases of bacterial meningitis in the Children's Hospital of Tunis. The serogroup distribution, antibiotic susceptibility and antigenic and molecular characteristics of $\mathrm{N}$. meningitidis isolates were determined in patients aged 3 days-13 years between February 1998 and June 2013. In all 107 invasive strains of N. meningitidis were isolated. Reduced susceptibility to penicillin $\mathrm{G}$ was seen in $55.7 \%$ of isolates, with a low level of resistance in all cases; $28.4 \%$ showed a low level of resistance to amoxicillin. Serogroup B isolates were the most frequent (80.4\%), followed by serogroups $C(12.2 \%)$ and $A(5.6 \%)$. Isolates of serogroup $A$ had the same antigenic formula $(A: 4: P 1.9)$, the same variable regions VR1, VR2 and VR3, and belonged to the same clonal complex (CC5). Isolates of serogroups B and C were more heterogeneous with several antigenic formulae. The most frequent clonal complex in these isolates was CC35. Serogroup B accounted for a large percentage of our isolates with marked diversity.

Caractérisation de souches invasives de Neisseria meningitidis isolées à l'Hôpital d'enfants de Tunis, en Tunisie

RÉSUMÉ La bactérie Neisseria meningitidis, I'une des causes principales de méningite bactérienne et d'autres infections graves, est responsable d'environ un tiers des cas de méningite bactérienne à l'Hôpital d'enfants de Tunis. La distribution par sérogroupe, la sensibilité aux antibiotiques et les propriétés antigéniques et moléculaires des isolats de N. meningitidis ont été déterminées chez des patients âgés de 3 jours à 13 ans entre février 1998 et juin 2013 . En tout, 107 souches invasives de N. meningitidis ont été isolées. Une sensibilité réduite à la pénicilline G a été observée dans $55,7 \%$ des isolats, avec un bas niveau de résistance pour tous les cas; et 28,4\% ont montré un bas niveau de résistance à I'amoxicilline.LesisolatsdusérogroupeBétaientlesplusfréquents(80,4\%), suivisparlessérogroupes C (12,2\%)etA(5,6\%). Les isolats du sérogroupe A avaient la même formule antigénique(A:4:P1.9), les mêmes régions variables VR1, VR2 et VR3, et appartenaient au même complexe clonal (CC5). Les isolats des sérogroupes B et C étaient davantage hétérogènes, avec plusieurs formules antigéniques. Le complexe clonal le plus fréquent de ces isolats était CC35. Le sérogroupe $B$ comptait pour un pourcentage élevé des isolats avec une diversité marquée. 


\section{Introduction}

Neisseria meningitidis is a major public health concern, particularly in children (1). Invasive meningococcal infections can occur in different clinical forms. Meningococcal meningitis is the most common entity and the outcome is usually good if patients are rapidly and well treated. However, the less common septic shock with the classical purpura fulminans is rapidly fatal $(1,2)$. The case-fatality rate of invasive disease is $\sim 10 \%$ in treated cases but varies widely depending on the clinical presentation and the infecting isolate. The highest case-fatality rates are observed in meningococcaemia without meningitis $(2,3)$.

The natural reservoir of $N$. meningitidis is the human nasopharyngeal mucosa. The carriage rate of N. meningitidis is < $1 \%$ in children younger than 4 years (4).

Unencapsulated isolates are commonly found in the nasopharynx in asymptomatic carriers but rarely cause invasive disease. Carriage induces a systemic humoral response, which is strain specific. Usually, invasive meningococcal isolates are encapsulated (5). The capsular polysaccharide is the major virulence factor for this bacterium. The composition of the capsule defines 12 different serogroups.

Meningococcal infections can be avoided using capsule-based vaccines. However, such vaccines are serogroup specific. Serogroups included in meningococcal vaccines are $\mathrm{A}, \mathrm{C}, \mathrm{W}$ and $\mathrm{Y}$. Two types of capsule-based vaccines are currently available $(6,7)$. The first is the meningococcal polysaccharide vaccine that has been available since 1970 (8). More recently, meningococcal conjugate vaccines have been developed (3). In addition, protein-based vaccines targeting serogroup $B$ isolates have been licensed in Europe, Canada, US and Australia (9).

Few data are available from North African countries about serogroup distribution and molecular characterization of N. meningitidis, particularly in children $(10,11)$. North African countries are located between sub-Saharan Africa, where isolates of serogroups A and W are responsible for periodic epidemics of meningococcal meningitis (12) and Europe, where isolates of serogroup B are predominant and responsible for sporadic cases of meningococcal invasive diseases (13). In North African countries, serogroup A and B isolates are predominant. Serogroup A strains are homogeneous and have the same antigenic formula, A:4:P1.9 $(2,10,11,14)$, as the pandemic clone that caused large epidemics in many African countries within the meningitis belt between 1990 and 1997 (14,15). In Tunisia, previous studies have involved a small number of isolates $(n=23)$, and have demonstrated that serogroup $B$ is predominant among invasive N. meningitidis isolates (2). The multi- component meningococcal B vaccine $(4 \mathrm{CMen} B)$ is not yet licenced in Tunisia, so a study of a larger collection of isolates allows us to better guide the prophylaxis and specify possible largescale vaccination. $N$ meningitis is one of the commonest organisms responsible for meningitis in our country. However, few data on the isolation rate and antibiotic susceptibility pattern are available. Such data are valuable for the empirical treatment of patients.

The aim of this study was to explore the serogroup distribution, antibiotic susceptibility and antigenic and molecular diversity of meningococcal isolates in a paediatric population in Tunisia in order to guide the empirical treatment and prophylaxis of invasive meningococcal diseases.

\section{Methods}

\section{Bacterial isolates}

We studied 107 N. meningitidis isolates obtained from clinical specimens at the Children's Hospital of Tunis from February 1998 to June 2013. After storage at $-80^{\circ} \mathrm{C}$, bacterial isolates were grown at $37^{\circ} \mathrm{C}$ in $5 \% \mathrm{CO}_{2}$ in $\mathrm{GC}$ medium base (Difco, Bordeaux, France) with Kellogg supplements. Culturing, identification and typing of the isolates are all part of the routine management and surveillance of meningococcal disease according to the guidelines of the Tunisian Department of Health.

\section{Antibiotic susceptibility}

Antibiotic susceptibility was performed by the disc diffusion method and included penicillin G, amoxicillin, cefotaxime, chloramphenicol and rifampin. Decreased susceptibility to beta-lactam antibiotics was detected using a $5-\mu \mathrm{g}$ oxacillin disc. The minimum inhibitory concentrations (MICs) of these antibiotics were defined by E-test methods (bio-Mérieux, Marcy l'Etoile, France) on Mueller-Hinton agar (Becton Dickinson, Franklin Lakes, NJ, USA) supplemented with $5 \%$ sheep blood and incubated at $37^{\circ} \mathrm{C}$ in $5 \% \mathrm{CO}_{2}$ for 18-24 h. Results were interpreted according to the Antibiogram Committee of the French Society for Microbiology (CA-SFM) guidelines (www.sfmmicrobiologie.org). Beta-lactamase was detected using a nitrocefin disc (bio-Mérieux). Internal quality control for antimicrobial susceptibility testing was performed using Pseudomonas aeruginosa ATCC 27553, Escherichia coli ATCC 25922 and Staphylococcus aureus ATCC 25923 strains according to CASFM guidelines.

\section{Serological typing}

Serogroups were determined for all isolates by slide agglutination using specific antibodies of $N$. meningitidis serogroups A, B, C, W and Y (Pastorex Meningitis; BioRad, France). Isolates were sent to the Institut Pasteur, Paris, France for phenotyping (serotypes and serosubtypes), which was determined for 56 isolates that were successfully recovered before February 2007 (41 serogroup B, 8 serogroup C, 6 serogroup $A$ and 1 serogroup $Y$ ). Phenotyping was 


\begin{tabular}{lccccc}
\hline $\begin{array}{l}\text { Table } 1 \text { Antibiotic susceptibility of } \mathbf{1 0 7} \text { invasive Neisseria meningitidis strains } \\
\text { Antibiotics }\end{array}$ & Breakpoints & $\begin{array}{c}\text { MIC range } \\
(\mathbf{m g} / \mathbf{L})\end{array}$ & Susceptible & $\begin{array}{c}\text { No. (\%) of isolates } \\
\text { Intermediate }\end{array}$ & Resistant \\
Penicillin G & $<0.125 />1$ & $0.023-1$ & $47(44.3)$ & $60(55.7)$ & 0 \\
Amoxicillin & $\leq 0.25 />2$ & $0.023-1.5$ & $77(71.6)$ & $30(28.4)$ & 0 \\
Cefotaxime & $\leq 0.12$ & $0.002-0.032$ & $107(100)$ & 0 & 0 \\
Chloramphenicol & $\leq 2 />4$ & $0.38-3$ & $104(97.7)$ & $3(2.8)$ & 0 \\
Rifampin & $\leq 0.25$ & $0.002-0.25$ & $107(100)$ & 0 & 0 \\
\hline
\end{tabular}

MIC = minimum inhibitory concentration.

performed using whole-cell ELISA, as previously described $(16,17)$. Sera for 6 serotypes $(1,2 \mathrm{a}, 2 \mathrm{~b}, 4,14,15)$ and 13 serosubtypes (P1.1, 2, 4-7, 9, 10 and 12-16) were tested. Antigenic formula was determined by the combination of serogroup: serotype: serosubtype.

\section{Molecular typing}

Genomic DNA extraction of meningococcal isolates was performed using the thermal shock method. The DNA extracted was stored at $-20^{\circ} \mathrm{C}$. All isolates were genogrouped using a capsule multiplex polymerase chain reaction (PCR) (18). Only isolates before February $2007(n=56)$ were further genotyped by porA sequencing and multilocus sequence typing (MLST). For MLST and porA sequencing, gene sequences were amplified, purified and sequenced as previously described $(19,20)$. Alleles, sequence types (STs) and clonal complexes (CCs) were assigned using the Neisseria MLST database (http://pubmlst.org/neisseria). The deduced amino acid sequences of variable regions VR1 and VR2 were assigned geno-subtype numbers according to the N. meningitidis PorA variable regions database (http://neisseria.org/ $\mathrm{nm} /$ typing/pora). The sequences of VR3 variants were classified according to the sequences described by Clarke etal. (21).

\section{Results}

Between February 1998 and June 2013, 107 invasive isolates of N. meningitidis were isolated from cerebrospinal fluid $(n=92 ; 86 \%)$ and blood $(n=$ $14 ; 13.1 \%)$. One isolate $(0.9 \%)$ was isolated from articular puncture. The patients' age ranged from 3 days to 13 years $($ mean $=3.2$ years; median $=2.3$ years) and gender ratio (male/female) was 1.26 .

Beta-lactam susceptibility testing showed that $55.7 \%$ of $N$. meningitidis isolates had decreased susceptibility to penicillin $\mathrm{G}$ (called hereafter MDSP) $\left(\mathrm{MIC}_{90}=0.5 \mathrm{mg} / \mathrm{L}\right)($ Table 1$)$. Among the MDSP, 30 isolates (28.4\%) had

\begin{tabular}{|c|c|c|c|c|c|}
\hline Antigenic formula ${ }^{a}(n)$ & PorA VR1 & PorA VR2 & PorA VR3 & ST & $\mathrm{CC}$ \\
\hline C:2a:P1.5,2 (1) & 5 & 2 & $36-2$ & & \\
\hline C:NT:P1.5,2 (1) & & & & SI-II & $\mathrm{CC} 11$ \\
\hline C:2a:P1.5 (1) & & & & ST-2780 & \\
\hline C:NT:NST (1) & $7-4$ & $14-6$ & $35-1$ & ST-1031 & CC334 \\
\hline C:4:NST (1) & $7-2$ & $13-1$ & $35-1$ & CT & \\
\hline C:4:P1.13 (2) & $7-2$ & 13 & 35 & $51-2 / 8$ & CC35 \\
\hline C:4:P1.14 (1) & $22-1$ & 14 & 38 & ST-809 & \\
\hline
\end{tabular}

${ }^{a}$ Serogroup: serotype: serosubtype.

$C C=$ clonal complex $; N S T=$ non-serosubtypeable $; N T=$ non-typeable $; S T=$ sequence type $; R=$ variable region.

reduced susceptibility to amoxicillin. However, no isolate was beta-lactamase-producing and all were susceptible to cefotaxime (Table 1). Three (2.8\%) isolates had reduced susceptibility to chloramphenicol (Table 1).

Serogroup B was the most frequent ( $n=86 ; 80.4 \%)$, followed by serogroup $\mathrm{C}(n=13 ; 12.2 \%)$ and serogroup $\mathrm{A}(n=$ 6; 5.6\%). Two isolates (1.8\%) belonged to serogroup Y.

ELISA showed that all 6 serogroup A isolates had the same antigenic formula (A:4:P1.9). The porA sequencing revealed the same variable regions VR 1 (20), VR2 (9) and VR3 (35-1). By MLST, serogroup A isolates belonged to CC5 but were of 2 sequence types (4 isolates were ST-7 and 2 were ST5832).

Two serogroup $\mathrm{C}$ isolates were of serotype $2 \mathrm{a}, 4$ of serotype 4 and 2 were nontypeable (NT). Several serosubtypes were detected among these isolates and 7 different antigenic formulae were obtained (Table 2). The porA sequencing allowed us to predict the variable regions VR1, VR2 and VR3 that define the subtypes for all those isolates. Genotyping by MLST showed that serogroup $\mathrm{C}$ isolates belonged to 5 different STs that were clustered into 3 CCs, among which CC35 was the most frequent $(n=4,50 \%)$ (Table 2). Three strains belonged to CC11 and had the same antigenic formula, P1.5,2 (Table 2). The serogroup $Y$ isolate was NT and non-serosubtypeable (NST) and belonged to ST-167 (CC167). porA 
sequencing revealed variable regions VR1 (5-1), VR2 (10-1) and VR3 (362).

Serogroup B isolates were predominant (41 of 56 isolates; $73 \%$ ) and were heterogeneous at the phenotypic level (Table 3). Six serotypes and 8 serosubtypes were detected among these isolates. However, most of them were $\mathrm{NT}(n=20)$ or NST $(n=11)$. Isolates belonging to serogroup B showed highly heterogeneous structure with 16 different combinations of serotype: serosubtype. The antigenic formula B:NT:P1.14 was the most frequent $(n=7)$. The por $A$ sequencing revealed sequences of VR1, VR2 and VR3 in all serogroup B isolates except 2 that failed to show PCR amplification for porA and may correspond to a PorAnegative isolate. VR1, VR2 and VR3 regions showed even more diversity than that revealed by serological typing with 8, 10 and 7 different sequences respectively (Table 3 ). MLST confirmed this diversity at the genetic level. Twenty-three different STs that were clustered into 12 distinct CCs were obtained. In 2 isolates, new sequences not belonging to any known CC were identified (designated as types ST3452 and ST-3453 and saved at the pubMLST database in the Tunisian collection) (Table 3). The most frequent $\mathrm{CC}$ among serogroup $\mathrm{B}$ isolates was CC35 (10 isolates; $24.4 \%$ ), which were grouped into 3 STs (ST-35, ST3451 and ST-5806). However, the hyperinvasive CC41/44, CC32 and CC269 were only represented by 2 (4.9\%), 4 (9.7\%) and 1 (2.4\%) of the Tunisian isolates, respectively.

In total, the most frequent $\mathrm{CC}$ among the 56 genotyped isolates was CC35, which accounted for 25\% (14 isolates of serogroups $\mathrm{B}$ and $\mathrm{C}$ respectively) (Table 4). The hyperinvasive lineages (CC5, CC11, CC32, CC41/44 and CC269) were represented by 18 isolates (32\%), regardless of the serogroups. There were 12 isolates (24\%) in serogroups B and C.

\section{Discussion}

N. meningitidis is a frequent cause of invasive bacterial disease in children, especially meningitis. The annual incidence of meningococcal disease varies from 0.5 to $6 / 100000$ inhabitants for developing countries (22). In sub-Saharan Africa the incidence can be much higher. The highest incidence is seen in countries of the meningitis belt, where it can be as high as 10 to $1000 / 100000$ inhabitants (22). Some studies have been conducted in Algeria, Morocco and Tunisia with regard to phenotyping and genotyping, but none was large enough to define the annual incidence in these countries or to allow good typing of the strains involved $(1,2,10,11)$.

Before the introduction of Haemophilus influenzae serotype $b$ (Hib) vaccine in the national vaccine programme in Tunisia, N. meningitidis was the third most common cause of bacterial meningitis $(23,24)$. After inclusion of $\mathrm{Hib}$ vaccine in the national immunization calendar, N. meningitidis has become the second most frequent cause of bacterial meningitis after Streptococcus pneumoniae (data presented at the Meningitis Research Foundation International Conference: Meningitis and septicaemia in children and adults, London, 2009).

There is little information regarding decreased antibiotic susceptibility of meningococcal isolates from African countries (25). The first isolate of MDSP was described in Spain in 1985 and their numbers have been increasing since then.. In this study, we found that $55.7 \%$ of the strains were MDSP, however, none of them exhibited betalactamase activity and all isolates were susceptible to cefotaxime. In a previous study in Tunisia, $34 \%$ of the strains were MDSP (26). This is a high percentage of MDSP compared to that in French (34\%) and Canadian (21.7\%) studies $(27,28)$. However, in Spain, the percentage of MDSP is higher (67\%) (29). In other countries, it was found to be lower and accounted $3.5 \%$ in Algeria (11), 4.3\% in Morocco (30), and $24.6 \%$ in Portugal (31). As expected for the African countries, rifampicin remained consistently active. Studies from France (27) showed rare resistant isolates.

Meningococcal serogroup distribution differs between regions and countries (22). Isolates of serogroup B and to a lesser extent serogroup $\mathrm{C}$ are predominant in Europe and America $(22,32)$. Serogroups A and W are predominant in the sub-Saharan meningitis belt. Additionally, serogroup X has been isolated in that region, while isolates of serogroup B are rare, if any (33). More recently, serogroup C isolates of a new sequence type (ST10217) were responsible for outbreaks in Northern Nigeria (34). Our data suggest that, unlike the sub-Saharan countries, serogroup B is frequent in Tunisia. Indeed, serogroup B was the most frequent serogroup in our study followed by serogroups $\mathrm{C}$ and $\mathrm{A}$. This distribution pattern is similar to the serogroup distribution in Morocco $(10,11)$.

All serogroup A isolates belonged to $\mathrm{CC} 5$ with the same phenotype (A:4:P1.9). The CC5 isolates dominated $(74.8 \%)$ among meningococcal isolates from countries of the African meningitis belt and were remarkably homogeneous in their PorA (33). As in Europe and America, in our study, serogroup $B$ was the most frequent followed by isolates of serogroup C. However, the phenotypes and genotypes of the circulating isolates differed from those observed in Europe and America (27,35). Isolates of serogroup B display a remarkable heterogeneity. In fact, we found 16 different antigenic formulae (serotype: subtype), belonging to $23 \mathrm{STs}$ and $12 \mathrm{CCs}$. The isolates belonging to CC35 were the most frequent in both serogroups $\mathrm{B}$ and $\mathrm{C}$ and accounted for $25 \%$ of all the genotyped isolates. This genotype has been rarely found among invasive 


\begin{tabular}{|c|c|c|c|c|c|}
\hline Antigenic formula ${ }^{a}(n)$ & VR1 & VR2 & VR3 & ST & $\mathrm{CC}$ \\
\hline \multirow[t]{2}{*}{ B:NT:NST (2) } & 22 & $16-36$ & $37-1$ & ST-3452 & UA \\
\hline & & & & ST-3453 & UA \\
\hline \multirow[t]{2}{*}{ B:2a:P1.5 (2) } & $5-11$ & $10-8$ & $36-2$ & ST-11 & \multirow{2}{*}{$\mathrm{CC} 11$} \\
\hline & & & & ST-1190 & \\
\hline B:4:P1.14 (1) & 22 & 14 & 36 & \multirow[t]{4}{*}{ ST-162 } & \multirow{4}{*}{$\mathrm{CC} 162$} \\
\hline \multirow[t]{3}{*}{ B:NT:P1.14 (3) } & $22-1$ & 14 & 36 & & \\
\hline & 22 & 14 & $36-2$ & & \\
\hline & 22 & 14 & 36 & & \\
\hline B:NT:P1.14 (1) & 22 & 14 & 36 & ST-5805 & \\
\hline B:NT:NST (1) & $5-2$ & $10-2$ & $36-2$ & ST-3449 & $\mathrm{CC} 18$ \\
\hline B:1:P1.14 (1) & 22 & 14 & 36 & ST-3114 & CC213 \\
\hline B:NT:P1.16 (1) & 21 & 16 & $37-1$ & ST-269 & CC269 \\
\hline B:NT:NST (1) & & & & ST-1118 & \multirow{5}{*}{$\mathrm{CC} 32$} \\
\hline B:NT:P1-5-2 (1) & 5 & 2 & $36-2$ & ST-33 & \\
\hline B:4:P1.14 (1) & $22-1$ & $14-1$ & 38 & ST-5331 & \\
\hline B:4:NST (1) & $5-2$ & 2 & $36-2$ & ST-5804 & \\
\hline B:4:P1-14 (1) & $22-1$ & 14 & 38 & & \\
\hline \multirow[t]{2}{*}{ B:NT:P1.14 (2) } & $22-1$ & 14 & 40 & ST-3451 & \multirow{6}{*}{ CC35 } \\
\hline & & & 38 & & \\
\hline B:14:P1.14 (3) & $22-1$ & 14 & 38 & \multirow{3}{*}{ ST-35 } & \\
\hline B:4:P1.2 (2) & $22-1$ & 2 & $36-2$ & & \\
\hline B:NT:P1.14 (1) & $22-1$ & 14 & 38 & & \\
\hline B:4:P1-14 (1) & $22-1$ & 14 & 38 & ST-5806 & \\
\hline B:NT:NST (1) & $7-2$ & $13-1$ & $35-1$ & ST-3448 & CC364 \\
\hline B:1:P1-6 (1) & $18-3$ & 3 & 38 & ST-206 & \multirow{2}{*}{ CC $41 / 44$} \\
\hline B:4:P1-4-10 (1) & $7-2$ & 4 & 37 & $\mathrm{ST}-41$ & \\
\hline B:1:NST (1) & 5 & $10-2$ & $36-2$ & \multirow{2}{*}{ ST-1946 } & \multirow{2}{*}{ CC461 } \\
\hline B:1:P1-10 (3) & $5-2$ & $10-2$ & $36-2$ & & \\
\hline B:NT:P1-2 (1) & 5 & 2 & $36-2$ & ST-2209 & \multirow{2}{*}{ CC60 } \\
\hline B:NT:P1-5-2 (2) & $5-2$ & 2 & $36-2$ & ST-60 & \\
\hline B:15:NST (2) & 21 & $16-36$ & $37-1$ & \multirow{3}{*}{ ST-3327 } & \multirow{3}{*}{ CC865 } \\
\hline B:NT:NST (2) & 21 & $16-36$ & 37 & & \\
\hline B:NT:P1-16 (1) & 21 & $16-36$ & $37-1$ & & \\
\hline
\end{tabular}

${ }^{a}$ Serogroup: serotype: serosubtype.

$C C=$ clonal complex $; N S T=$ non-serosubtypeable; $N T=$ non-typeable; $S T=$ sequence type; $U A=$ unassigned $; V R=$ variable region.

isolates in Europe (32). A study on invasive strains of serogroups $B$ and $C$ has shown that CC35 strains lack the fetA gene (36). Further studies such as FetA VR sequencing are needed to explore this hypothesis for the Tunisian strains and to analyse their pathogenesis. One striking aspect is that, unlike Europe, where $77 \%$ of the isolates belong to the hyperinvasive $\mathrm{CC} 8, \mathrm{CC} 11, \mathrm{CC} 32$, CC41/44 and CC269 (37), our study showed that these CCs were only present in $24 \%$ of all genotyped isolates of serogroups B and C. The hyperinvasive isolates were predominant not only in Europe but also in New Zealand, Brazil and North America (3).

Despite the absence of molecular categorization of the entire collection studied, this is believed to be the largest epidemiological analysis of meningococcal invasive strains in
Tunisia. Our study revealed great heterogeneity of N. meningitides isolates, particularly among serogroup $\mathrm{B}$. This heterogeneity can be explained by the geographical position of Tunisia and the travel pattern of people leaving or visiting the country. We identified two new sequence types (ST-3452 and ST-3453) that were saved at the pubMLST database in the Tunisian collection. Epidemiology 


\begin{tabular}{|c|c|c|c|c|}
\hline \multirow[t]{2}{*}{$\mathrm{CC}$} & \multicolumn{4}{|c|}{ N. meningitidis serogroups (n) } \\
\hline & $\mathrm{A}(n=6)$ & B $(n=41)$ & $C(n=8)$ & $Y(n=1)$ \\
\hline CC35 & - & 10 & 4 & - \\
\hline CC5 & 6 & - & - & - \\
\hline $\mathrm{CCl1}$ & - & 2 & 3 & - \\
\hline CC32 & - & 4 & - & - \\
\hline CC41/44 & - & 2 & - & - \\
\hline CC269 & - & - & - & - \\
\hline New & - & 2 & - & - \\
\hline Other ${ }^{a}$ & - & 20 & 1 & 1 \\
\hline
\end{tabular}

${ }^{a}$ CCC162 (5); CC18 (1); CC213 (7); CC364 (1); CC461 (4); CC60 (3); CC865 (5).

of meningococcal infections in North African countries is different from that in sub-Saharan countries. A surveillance network is needed to establish a reliable vaccination policy, especially for the use of conjugate vaccines or newly developed protein vaccines against serogroup B isolates (4).

\section{Acknowledgements}

We thank Dr Jean-Michel Alonso (Unité des Neisseria and Centre National de Référence des Méningocoques, Institut Pasteur, Paris) for discussion and support for this work.
Funding: This work was supported in part by WHO (EMRO/TDR Small Grants Scheme for Operational Research in Tropical and Other Communicable Diseases (SGS05/59), the French Ministry of Foreign Affairs (3C2-002/E) and the Pasteur Institute, Paris.

Competing interests: None declared.

\section{References}

1. Menif K, Hamdi A, Khaldi A, Bouziri A, Kazdaghli K, Bel Hadj $S$, et al. Prise en charge du purpura fulminans a propos de 21 cas: retard diagnostique et problemes therapeutiques [Management of purpura fulminans apropos of 21 cases: diagnostic delay and therapeutic problems]. Tunis Med. 2007 May;85(5):371-5. PMID:17657920

2. Smaoui H, Saguer A, Bouziri A, Fourati S, Chahed MK, Ben Jaballah $\mathrm{N}$, et al. Les infections invasives a Neisseria meningitidis chez l'enfant a Tunis: a propos de 79 cas. [Neisseria meningitidis invasive infections in children in Tunis: about 79 cases]. Arch Inst Pasteur Tunis. 2011;88(1-4):35-41. PMID:23461141

3. Khatami A, Pollard AJ. The epidemiology of meningococcal disease and the impact of vaccines. Expert Rev Vaccines. 2010 Mar;9(3):285-98. PMID:20218857

4. Caugant DA, Tzanakaki G, Kriz P. Lessons from meningococcal carriage studies. FEMS Microbiol Rev. 2007 Jan;31(1):52-63. PMID:17233635

5. Jounio U, Saukkoriipi A, Bratcher HB, Bloigu A, Juvonen R, Silvennoinen-Kassinen $S$, et al. Genotypic and phenotypic characterization of carriage and invasive disease isolates of Neisseria meningitidis in Finland. J Clin Microbiol. 2012 Feb;50(2):264-73. PMID:22135261

6. Zimmer SM, Stephens DS. Meningococcal conjugate vaccines. Expert Opin Pharmacother. 2004 Apr;5(4):855-63. PMID:15102568

7. Taha MK, Alonso JM. Meningococcal vaccines: to eradicate the disease, not the bacterium. Hum Vaccin. 2007 JulAug;3(4):149-52. PMID:17643068

8. Vaccine Information Statement. Meningococcal ACWY Vaccines (3/31/2016). 42 U.S.C. § 300aa-26. (http://www.cdc. gov/vaccines/hcp/vis/vis-statements/mening.pdf, accessed 1 May 2016).
9. Gasparini R, Amicizia D, Domnich A, Lai PL, Panatto D. Neisseria meningitidis $\mathrm{B}$ vaccines: recent advances and possible immunization policies. Expert Rev Vaccines. 2014 Mar;13(3):345-64. PMID:24476428

10. Zerouali K, Elmdaghri N, Boudouma M, Benbachir M. Serogroups, serotypes, serosubtypes and antimicrobial susceptibility of Neisseria meningitidis isolates in Casablanca, Morocco. Eur J Clin Microbiol Infect Dis. 2002 Jun;21(6):4835. PMID:12111610

11. Tali-Maamar H, Rahal K. Etude des souches de Neisseria meningitidis isolées en Algérie entre 1992 et 2001. [Study of Neisseria meningitidis Neisseria meningitidis strains collected in Algeria between 1992 and 2001]. Med Mal Infect. 2003 Dec;33(12):640-3.

12. Taha MK, Parent Du Chatelet I, Schlumberger M, Sanou I, Djibo S, de Chabalier F, et al. Neisseria meningitidis serogroups W135 and A were equally prevalent among meningitis cases occurring at the end of the 2001 epidemics in Burkina Faso and Niger. J Clin Microbiol. 2002 Mar;40(3):1083-4. PMID:11880446

13. Trotter CL, Chandra M, Cano R, Larrauri A, Ramsay ME, Brehony C, et al. A surveillance network for meningococcal disease in Europe. FEMS Microbiol Rev. 2007 Jan;31(1):2736. PMID:17168995

14. Nejmi S, Belhaj A, Guibourdenche M, Riou JY. Etude de quatre vingt dix souches de Neisseria meningitidis de serogroupe A isolées du liquide céphalorachidien (25) et du rhino- pharynx (65) au Maroc. [Study of ninety strains of serogroup A Neisseria meningitidis isolated from cerebrospinal fluid (25) and rhinopharynx (65) in Morocco (December 1989-April 1990)]. Pathol Biol (Paris). 1992;10:993-8. PMID:1299815 
15. Guibourdenche M, Høiby EA, Riou JY, Varaine F, Joguet C, Caugant DA. Epidemics of serogroup A Neisseria meningitidis of subgroup III in Africa, 1989-94. Epidemiol Infect. 1996 Apr;116(2):115-20. PMID:8620901

16. Abdillahi H, Poolman J-T. Definition of meningococcal class 1 OMP subtyping antigens by monoclonal antibodies. FEMS Microbiol Immunol. 1988 Dec;1(3):139-44. PMID:3152545

17. Abdillahi H, Poolman J-T. Whole-cell ELISA for typing Neisseria meningitidis with monoclonal antibodies. FEMS Microbiol Lett. 1987 Dec;48(3):367-71.

18. Taha MK. Simultaneous approach for nonculture PCR-based identification and serogroup prediction of Neisseria meningitidis. J Clin Microbiol. 2000 Feb;38(2):855-7. PMID:10655397

19. Maiden MC, Bygraves JA, Feil E, Morelli G, Russell JE, Urwin $\mathrm{R}$, et al. Multilocus sequence typing: a portable approach to the identification of clones within populations of pathogenic microorganisms. Proc Natl Acad Sci U S A. 1998 Mar 17;95(6):3140-5. PMID:9501229

20. Taha M-K, Giorgini D, Ducos-Galand M, Alonso JM. Continuing diversification of Neisseria meningitidis W135 as a primary cause of meningococcal disease after emergence of the serogroup in 2000. J Clin Microbiol. 2004 Sep;42(9):4158-63. PMID:15365005

21. Clarke SC, Diggle MA, Mölling P, Unemo M, Olcén P. Analysis of PorA variable region 3 in meningococci: implications for vaccine policy? Vaccine. 2003 Jun 2;21(19-20):2468-73. PMID:12744880

22. Harrison LH, Trotter CL, Ramsay ME. Global epidemiology of meningococcal disease. Vaccine. 2009 Jun 24;27 Suppl 2:B51-63. PMID:19477562

23. Khalifa $\mathrm{AB}$, Mastouri $\mathrm{M}$, Abdallah HB, Noomen $\mathrm{S}$, Kheder $\mathrm{M}$ Les méningites purulentes dans la région de Monastir, Tunisie (1999-2006): aspects bactériologiques et état de résistance aux antibiotiques. [Acquired bacterial meningitis in Monastir region, Tunisia (1999-2006): bacteriological aspects and susceptibility patterns]. Bull Soc Pathol Exot. 2011 Feb;104(1):42-8. PMID:20835902

24. Maalej SM, Kassis M, Rhimi FM, Damak J, Hammami A. Bactériologie des méningites communautaires dans la région de Sfax, Tunisie (1993-2001). [Bacteriology of community acquired meningitis in Sfax, Tunisia (1993-2001)]. Med Mal Infect. 2006 Feb;36(2):105-10. PMID:16459040

25. Hedberg ST, Fredlund $\mathrm{H}$, Nicolas $\mathrm{P}$, Caugant DA, Olcén P, Unemo M. Antibiotic susceptibility and characteristics of Neisseria meningitidis isolates from the African meningitis belt, 2000 to 2006: phenotypic and genotypic perspectives. Antimicrob Agents Chemother. 2009 Apr;53(4):1561-6. PMID:19188396

26. Saguer A, Smaoui H, Kechrid A. Typage phénotypique et étude de la sensibilité aux antibiotiques de Neisseria meningitidis isolées à l'Hôpital d'Enfants de Tunis (Mars 1994 - février 2004). [Phenotyping and antibiotic susceptibility's study of Neisseria meningitidis strains isolated at the "Hôpital d'Enfants" of Tunis]. Tunis Med. 2006;84:730-3.

27. Marc LaForce F, Ravenscroft N, Djingarey M, Viviani S. Epidemic meningitis due to Group A Neisseria meningitidis in the African meningitis belt: a persistent problem with an imminent solution. Vaccine. 2009 Jun 24;27 Suppl 2:B13-9. PMID:19477559

28. Brown EM, Fisman DN, Drews SJ, Dolman S, Rawte P, Brown S et al. Epidemiology of invasive meningococcal disease with decreased susceptibility to penicillin in Ontario, Canada, 2000 to 2006. Antimicrob Agents Chemother. 2010 Mar;54(3):1016-21. PMID:20086160

29. Pascual A, Joyanes P, Martinez-Martinez L, Suarez AI, Perea EJ. Comparison of broth microdilution and E-test for susceptibility testing of Neisseria meningitidis. J Clin Microbiol. 1996 Mar;34(3):588-91. PMID:8904420

30. Zerouali K, Castelli P, Van Looveren M, El Mdaghri N, Boudouma M, Benbachir M, et al. Etude de souches de Neisseria meningitidis sérogroupe $B$ isolées à Casablanca par multilocus sequence typing et électrophorèse en champ pulsé. [Use of multilocus sequence typing and pulsed-field gel electrophoresis for the study of serogroup B Neisseria meningitidis isolates from Casablanca (Morocco)]. Pathol Biol (Paris). 2006 Apr;54(3):166-70. PMID:16442242

31. Ferreira E, Dias R, Caniça M. Antimicrobial susceptibility, serotype and genotype distribution of meningococci in Portugal, 2001-2002. Epidemiol Infect. 2006 Dec;134(6):1203-7. PMID:16740192

32. Levy C, Taha MK, Weil Olivier C, Quinet B, Lecuyer A, Alonso JM, et al.; Groupe des pédiatres et microbiologistes de I'Observatoire National des Méningites. Association of meningococcal phenotypes and genotypes with clinical characteristics and mortality of meningitis in children. Pediatr Infect Dis J. 2010 Jul;29(7):618-23. PMID:20168263

33. Caugant DA, Kristiansen PA, Wang X, Mayer LW, Taha MK, Ouédraogo R, et al. Molecular characterization of invasive meningococcal isolates from countries in the African meningitis belt before introduction of a serogroup A conjugate vaccine. PLoS One. 2012;7(9):e46019. PMID:23029368

34. Funk A, Uadiale K, Kamau C, Caugant DA, Ango U, Greig J. Sequential outbreaks due to a new strain of Neisseria meningitidis serogroup C in northern Nigeria, 2013-14. PLoS Curr. 201412 29;6:ecurrents.outbreaks.b50c2aaf1032b3ccade0fca0b63ee518. 10.1371/currents.outbreaks.b50c2aaf1032b3ccade0fca0b63ee518 PMID:25685621

35. Russell J-E, Urwin R, Gray S-J, Fox AJ, Feavers IM, Maiden MC. Molecular epidemiology of meningococcal disease in England and Wales 1975-1995, before the introduction of serogroup C conjugate vaccines. Microbiology. 2008 Apr;154(Pt 4):1170-7. PMID:18375809

36. Marsh J-W, O'Leary M-M, Shutt K-A, Harrison LH. Deletion of fetA gene sequences in serogroup $\mathrm{B}$ and $\mathrm{C}$ Neisseria meningitidis isolates. J Clin Microbiol. 2007 Apr;45(4):1333-5. PMID:17287336

37. Brehony C, Trotter CL, Ramsay ME, Chandra M, Jolley KA, van der Ende $A$, et al. Implications of differential age distribution of disease-associated meningococcal lineages for vaccine development. Clin Vaccine Immunol. 2014 Jun;21(6):847-53. PMID:24695776 